\title{
Managing suppliers for collection development: the UK higher education perspective
}

\section{David Ball}

\section{Introduction}

Publishing has traditionally been regarded as a profession for gentlemen. This is an outmoded term to be sure, but it conveys the impression of a trade that was not overly concerned about profit, of practitioners focused on some higher ideal. Librarians have also traditionally exhibited this trait of not focusing on money, perhaps by emulation, perhaps by an innate commitment to collaboration and the ideal of learning. This is epitomised in the title of the library journal devoted to the commercial nexus linking libraries, publishers and intermediaries, Against the Grain (www.against-the-grain.com/), which implies that its subject matter is somehow at odds with traditional professional concerns.

In contrast to the USA, such distaste may have been fostered by the long existence of retail price maintenance for books in many European countries, such as Austria, France, Germany, Greece, Holland, Italy, Portugal and Spain In Germany, for instance, publishers are legally required by the Buchpreisbindungsgesetz to set the price, including tax, at which books are sold to the end-user. The price remains fixed for a minimum of 18 months, or until a new edition is published (http://de.wikipedia.org/wiki/Buchpreisbindung). The UK form of retail price maintenance, the Net Book Agreement (NBA), enabled publishers to fix the prices at which books could be sold. Booksellers were not allowed to give discounts, except a fixed $10 \%$ discount under the so-called Library Licence. Libraries received the fixed discount on condition that they made their stock available to the public. This condition, obviously fulfilled by public libraries, was generally not considered too onerous by university librarians: virtually all allowed walk-in access to stock. The notable exception was Philip Larkin at Hull, who would not allow students of the local teacher-training institution access to the university library, and hence forfeited the 10\% discount (Hinton, 1993, 45): an example of the triumph of principle over economics.

The early 1990s saw the discounting of book prices by some of the larger bookselling chains, by the mid-1990s publishers were withdrawing support, and in 1997 the NBA was ruled illegal. This opened the way for the three-for-two offers and the heavy discounting by supermarkets and Amazon that are such a feature of the book trade today. The demise of the NBA also prompted academic and public libraries to seek better terms from their suppliers: booksellers were now expected to compete not only on quality of service but also, and perhaps more importantly for library and university managers, on price. The book budgets of probably all university libraries were easily big enough to fall within the purview of the European Union's procurement directives for public bodies (for an introduction and information on the current thresholds above which the directives apply, see the Office of Government Commerce (OGC) website: http://www.ogc.gov.uk/key crosscutting government policies the policy and legal framework.asp). Given the requirements of the directives, the application of the procurement discipline of the purchasing profession, whether through individual institutions or the university purchasing consortia, became more necessary. This of course is another instance of the trend, as the environment changes, for librarians to import and learn from the expertise of other professions: a current example is the widespread adoption of project management techniques, long used in the IT and other industries. (Guidance on the standard public procurement process is provided by the OGC, see http://www.ogc.gov.uk/policy_and_standards_framework_introduction_to_public_procureme nt.asp; information on the purchasing profession in the UK and internationally is given by the Chartered Institute of Purchasing and Supply (CIPS) at http://www.cips.org/en-gb/.)

This chapter will follow the adoption of this new procurement discipline by academic libraries since the demise of the NBA. It will first examine the standard procurement cycle, with 
particular reference to libraries and book supply (a more general approach is provided by the CIPS purchasing and supply management model at http://www.cips.org/en$\mathrm{gb} /$ resources/purchasingsupplymanagementmodel/). It then discusses library purchasing consortia and their contribution to managing and developing the library market place for books, identifying three phases of operation. It closes with some reflections on the future prospects of collection development.

\section{The Procurement Cycle}

The standard procurement cycle comprises, briefly, the following five elements: identifying the need, preparing the specification, finding the supplier, awarding the contract, measuring and monitoring performance. Following and understanding this cycle is fundamental to taking control of relationships with suppliers and of the market place (more detail on this process is given by Ball (2005a)).

\section{Identifying the need}

The first step is to determine precisely what is required, and on what basis it should be procured - bought, leased, hired, shared... With hard-copy information, the emphasis is on buying and servicing the physical product. With electronic information, libraries are generally buying a service not a product: the emphasis is on access and the terms that govern it. This is a fundamental difference. With hard copy, libraries are limited only by the law (for instance of copyright); they may buy, sell, lend, do anything with the information. With electronic information, libraries are restricted by the terms of the licences, which generally limit the uses and users of the information.

It should be noted that in much procurement for libraries, the users are not consulted directly about their needs: the budget-holders, librarians, act as proxies. This may lead to a concentration on the technical issues that affect the library, such as processing of books or electronic data interchange (EDI), rather than on those that directly affect the user, such as the functionality of e-book offerings.

\section{Preparing the specification}

Once the need has been identified, it has to be expressed in a specification. This specification is fundamental to any procurement: it informs potential suppliers of what is required, how, when, and to what standards. If the specification is wrong, there is no chance of satisfying adequately the procurement needs. It should contain enough information and detail to ensure that both suppliers and purchasers are addressing the same requirement, and that suppliers can cost fully the products or services required. However, except for technical compatibility, it should not be so overly specific, for instance in detailing procedures, that it prevents negotiation or discourages suppliers from proposing innovative solutions. Suppliers know their own business better than librarians do; over-specifying stifles creativity and the development of partnership, and hence decreases the potential benefits of any procurement.

It is important that the specification should also promote open and fair competition. It should not discriminate, explicitly or implicitly, against particular suppliers or products. For instance, it may be superficially attractive to prefer local suppliers. However, a relatively distant supplier that can meet the requirements (such as next-day delivery, response times) may in fact offer a higher quality service or a better price than the local supplier. A supplier should be judged on performance against the specification, not on the purchaser's preconceptions of how the goods or service should be supplied. This approach opens up competition, fostering lower prices and higher quality.

While each procurement is individual in nature, expressing an individual requirement, specifications should wherever possible adopt national or international standards or de facto standards (such as MARC). In the longer term, the adoption of standards leads to 
reductions in the costs of both goods and services. Suppliers are geared towards offering for instance shelf-ready books, with standard MARC records, LC subject headings, DDC class numbers and standard processing. They lose economies of scale and simplicity by having to classify to local schemes or to provide (as happened in one procurement) a particular shade of duck-egg blue spine labels.

Cost is obviously an important element of any procurement. The specification should as far as possible address whole-life costs: for instance when buying or leasing equipment, costs of consumables, call-outs and maintenance should be taken into account, as well as the purchase or lease price.

The specification also provides the yardstick for evaluating any tenders received, so should be capable of being turned into measurable criteria. Obviously, this is easier for some procurements than for others. The discounts offered by booksellers on a basket of books can be compared relatively easily one with another. However, concepts such as quality of service or the user-friendliness of a system are far more difficult to quantify. This should be borne in mind when drawing up any specification: how will one score suppliers against each other when evaluating their responses?

\section{Finding the supplier}

\section{The Tender}

Often the market place is approached through a tender process. In the UK, this process is governed by the European Union's procurement directives (underlying practice in other countries will generally be similar; pointers can be found through the national associations affiliated to the International Federation of Purchasing and Supply Management, see http://www.ifpmm.org/Membership/MbrAssoc.cfm). Issuing the tender document is the first step in a process leading to a contract between purchaser and suppliers. The involvement of procurement professionals from the start of the process is essential. A key element is the specification of requirements just discussed; this will in many cases be supplemented by a statement of the service levels required, e.g. for supply times or customer care, and any performance indicators.

The document also specifies the information required from the potential suppliers. This should include audited accounts, quality assurance accreditations, membership of professional organisations, qualifications and experience of key staff, evidence of commitment to staff development (ISO 9000, Investors in People, policies etc.), number of staff employed in key areas, and a list of major accounts. A selection from the last can be contacted for references on the performance of the supplier against key indicators.

A further important element required from potential suppliers is the price schedule. Several pricing models might be applied to library procurements:

- Fixed Price - This is the most obvious model and the easiest to evaluate. It is used for one-off purchases or commissions, such as consultancy.

- Discount from List Price - Hard-copy books and serials tend to be bought under this model, with intermediaries - booksellers and serials agents - offering a discount from the cover price. While ostensibly simple, some care has to be taken when evaluating suppliers under this model to check that they are quoting the same price; different approaches to exchange rates for instance can lead to distortions. Evaluation becomes even more complex when suppliers offer discounts that vary with the level of discount they themselves receive.

- Cost-Plus - In the past booksellers have tended to offer a single discount across the board. There is some risk for them in this model, since the discounts they receive from publishers or wholesalers vary: if customers order unexpectedly large numbers of titles 
attracting low or no discount, the bookseller will lose money. Cost-plus eliminates this risk: the supplier charges the price paid for the items and adds a fixed charge for the work carried out. This model has attractions for both sides: the supplier has a guaranteed return; the purchaser knows that the best price is achieved. However it can be difficult to audit and manage, and, with perhaps only one exception, has generally not been offered by library suppliers.

Management Fee - Increasingly library management systems suppliers are offering a facilities management service, where they not only supply the system but also manage it. This model is generally used in such cases.

\section{Evaluating the Suppliers}

Generally, there are four elements to be evaluated: the financial health of the supplier, the price quoted, quality, and the ability of the suppliers to meet the specification. Typically, a number of resources are used in the evaluation: published information and analyses (particularly financial), the returned tender documents, visits to suppliers' premises, customer references, and meetings to clarify the information provided.

Firstly, especially for contracts that are large or last for a number of years or are critical for carrying on the library's business, one will want to evaluate the financial viability of the potential suppliers. The companies' audited accounts give information on turnover, profits, and growth and performance trends. Organisations such as Dunn \& Bradstreet provide overviews of the financial health of a company, compared with any industry standards. Financial health is a pass-fail requirement. If there are justifiable doubts about the viability of a company, it should be rejected unless there are very good reasons to the contrary. No library will want to appoint a supplier that does not have the financial standing to invest in product development or may cease trading within the life of the contract.

It may also be inadvisable to award a large contract if it would form a significant proportion of a supplier's business: how will the supplier cope with the suddenly increased volume? It may be argued that the above tends to eliminate the small or new supplier, increasing the consolidation of the market. This is certainly a danger to be addressed in any tender, particularly in market places that are shrinking: it is not in the purchaser's interest to decrease competition.

Secondly, one will of course want to evaluate the price quoted, bearing in mind the different cost models discussed above, and the need to evaluate the cost over the whole life of the contract.

Thirdly, one will evaluate quality. This can be the most difficult area: quality is not easy to quantify, involving judgement rather than facts such as cost; moreover, one may well be in the position of judging the likely performance of a supplier with which one has had no dealings. There are some relatively concrete indicators, particularly accreditation under quality schemes such as ISO 9000 or Investors in People and membership of professional organisations. One may also take account of the qualifications and experience of key staff, and of staff development policies and programmes. Much information can also be gained from formal visits to suppliers' premises. These should be as structured as possible, with the team of evaluators having a checklist of quality measures under investigation.

References from existing customers are also valuable. However, it is advisable to chose from a list of major clients, for instance all those spending over a certain amount with the supplier, rather than from a list of referees. The latter will be chosen by the supplier to give a favourable report; the former can be picked according the purchaser's interests. One should also ask the reference sites chosen specific structured questions about performance and quality, such as supply times, rate of errors, customer care. 
Finally, one may wish to evaluate the ability of the supplier to meet the specification. This applies particularly in procurements that are complex, for instance of a library management system, or seek to develop new services, such as shelf-ready books or supplier selection. Suppliers may not provide initially all of the functionality or services required; one will therefore need to judge how close they are to being able to meet the requirements.

Apart from the pass/fail requirement of financial health, the above elements of cost, quality and ability to meet the specification will differ in importance, depending on the situation of the purchaser and the type of procurement; one will therefore wish to recognise these differences by weighting the three elements accordingly (a fully worked example of how one can apply weighting to complex decision-making is given by Ball (2005a)). In many cases, such as a contract for the supply of books, cost will be most important, and one might assign weightings of 40:30:30 respectively to the three elements. In other cases, for instance the procurement of a library management system, ability to meet the specification might be equally important; one might therefore apply weightings of 40:20:40.

\section{Awarding the Contract}

The deal is concluded. The obligations of the supplier and buyer, based on the specification, are written into a contract. The contract will normally be supplemented by service-level agreements and performance measures.

\section{Measuring and Monitoring Suppliers' Performance}

The procurement cycle is far from over after the contract has been awarded. Contract management, the process of ensuring that specification, service level agreements and performance measures are met over the period of the contract (which may be five years or more), is essential if suppliers are to be managed satisfactorily. This is generally achieved through quarterly or six-monthly contract review meetings with individual suppliers, who are expected to provide management information on the performance measures, drawn from the specification and detailed in the agreement. For a book contract these might include discounts achieved, time taken to supply books and to resolve queries, number of books supplied in error.

\section{Conclusion}

The above illustrates the procurement cycle. Fundamental to this cycle and its successful management is the specification of requirements: it is the basis both of selecting the best supplier(s) and of ensuring their performance throughout the life of the contract. It is crucial to produce a specification that reflects the purchaser's requirements accurately and fully, and in a form that can be quantified as far as possible. Writing the specification is not an easy process, but the time and effort expended at the start of the procurement cycle pay dividends throughout.

\section{Managing Suppliers and the Market Place: Library Purchasing Consortia in the UK} Turning from some of the techniques of procurement, a number of strategies have been adopted to manage suppliers and the market in which they operate. This section examines approaches to the procurement of hard-copy resources through traditional library purchasing consortia, perhaps the most useful tool for carrying out procurements.

Aggregation of purchasing power brings many advantages over and above leverage on price. New services, for instance the truly shelf-ready - catalogued, classified and processed book, have been negotiated through the strength of consortia. Quality of service is monitored closely and enhanced through continuing management of contracts based on tight specifications of service; pooled knowledge of suppliers' performance against these specifications lends force to this process. There are considerable savings in terms of the time needed by individual libraries to manage complex European procurement procedures and the resulting contracts. 
Consortia can be powerful entities, particularly when they take a holistic view uniting both print and electronic procurement: publishers produce and deal in both media; libraries integrate print and electronic forms in their service to users; they should integrate the procurement of them too. Consortia are the only library organisations that have a chance of affecting the marketplace; individual libraries certainly do not.

In some countries, such as the USA, where individual libraries have large book budgets and the ability to negotiate good discounts, and some European countries, where retail price maintenance applies to books, library consortia have concentrated on automation and resource sharing. These countries have seen as a natural progression the concentration of consortia on the collaborative procurement of electronic resources rather than hard copy (Nfila and Darko-Ampen 2002). However other countries such as Australia share the UK experience of hard-copy procurement (Baudinette 2004).

\section{Collaboration between Consortia}

The situation in library procurement for UK higher education is complex. There are seven regional purchasing consortia, covering together the whole of the UK, and with the majority of higher education libraries in active membership. Some of these, such as the Southern Universities Purchasing Consortium (SUPC, http://supc.procureweb.ac.uk ), have grown from consortia that handle procurement across the whole range of university activity. Others, such as North East and Yorkshire Academic Libraries (NEYAL, http://neyal.procureweb.ac.uk/public/home.htm) have grown from library collaboration, but have links to a wider university consortium. The value of procurement through their contracts is estimated at $£ 100 \mathrm{~m}$ per annum. All the regional consortia, together with the Research Council libraries and the British Library, form Procurement for Libraries.

Procurement for Libraries aims to be a forum for the exchange of experience between consortia, to offer a unified voice to the higher education sector, suppliers and other bodies, and to enhance procurement practice across the sector through staff development activities. It is also a forum where consortia can determine the appropriate level for any procurement, regional or national. The then Joint Procurement Policy and Strategy Group for HE, a body bringing together the general university purchasing consortia, established a protocol requiring a business case to be made evaluating the advantages and disadvantages of the national and the regional approach. Following this protocol, library consortia have generally adopted the regional approach for the supply of hard-copy resources: there are so few suppliers, particularly serials agents, that to award a national contract to only one or two might put the others out of business. Since 2009 however there has been a new strategy: under the Procurement for Libraries umbrella all the English purchasing consortia have undertaken a very successful joint tender for the supply of books and other materials.

Individual consortia may also be members of the International Coalition of Library Consortia (ICOLC; for more information and a list of member consortia see

http://www.library.yale.edu/consortia/); its focus is mainly on electronic resources.

\section{The Individual Consortium}

While size can be important for the individual consortium, in aggregating demand and providing libraries with a strong voice in negotiations with suppliers, it also brings problems. A UK higher education consortium may have more than 50 members, ranging from the small very specialist performing arts institution, through the medium-sized research-oriented university, to the teaching-oriented university with large numbers of undergraduates.

Each of these types of institution will have a very different focus - extensive serials holdings or large quantities of textbooks for instance - and require very different specialist resources. The large geographically defined consortium will need robust mechanisms for consulting its 
members and ensuring that their diverse requirements are reflected in any procurements. Generally, this is achieved by plenary meetings, held once or twice a year, which decide strategy, and working groups, with representatives from the different types of library, which undertake the detailed work of the procurement cycle. These working groups have the advantage of enabling a number of people to be involved and build up expertise in the procurement process, an example of the new skills increasingly required by the library and information profession.

Given the diversity of the geographically defined consortia, and their sometimes unwieldy numbers and spread, it may be argued that specialist consortia, representing only one type of library or a particular subject, could be more effective, and indeed obtain better prices for their members. However, it is possible to instigate joint specialist procurements by the regional consortia, through the mechanism of such groups as Procurement for Libraries discussed above. It is also possible to segment procurements by an individual large consortium, in order to develop specialist services.

\section{Traditional Procurement of Hard Copy}

One can identify three phases in the operation of library purchasing consortia in procuring books.

The first phase began in 1996 during the demise of the NBA, and unsurprisingly, given the prevailing restrictive terms of the Library Licence, concentrated on price. Booksellers are intermediaries. Publishers set the price at which they believe a book should retail, and offer a discount from that price to the booksellers that supply the end customer. This discount varies depending on the terms the bookseller can negotiate and the number of copies likely to be sold. Generally the bigger booksellers and the more popular titles attract the highest discounts. Only the booksellers and publishers know the discount models and terms. However discounts of $30-40 \%$ for the more popular academic titles are reportedly not uncommon.

The discounts that the library purchasing consortia can obtain from booksellers are therefore limited by a number of factors: the discount obtained by the bookseller, the efficiency of the bookseller in keeping costs down and the profit margin required by the bookseller. The NBA discount of $10 \%$ under the Library Licence was obviously not at all generous, and may have contributed to inefficiency and complacency within the trade. When the library purchasing consortia turned their attention to books in the mid-1990s, across-the-board discounts as high as $23 \%$ of the list price were obtained. This level of discount represented a saving of over $14 \%$ on the old NBA terms, and was ostensibly good news for library budgets. However it proved unsustainable; some suppliers had apparently underestimated the proportion of low- or no-discount titles bought by academic libraries and experienced some financial difficulties.

The second phase saw some correction in the level of discount offered, and focused on costs and quality of service. Ordering, receipting, cataloguing, classifying and servicing a book is a costly and routine process, and one that notoriously resulted in backlogs of new stock in libraries, which caused discontent among users. Booksellers, through economies of scale, were able to offer a fully shelf-ready service at a much lower cost than libraries were able to achieve: books would arrive catalogued, classified and processed, ready to go direct to the shelf on arrival. This is a classic case of successful outsourcing: routine processes, characterised by peaks and troughs of demand, can be carried out much more cheaply by specialist agencies. Libraries were however required to standardise their requirements, and suppliers to invest in equipment and staff, something that only the discipline and volume of business provided by the library purchasing consortia could achieve. 
One instance of improved quality of service achieved is the decrease in supply times. Typically in 2002/3 the average time taken to supply a book, from order to receipt, was over 38 calendar days; $5 \%$ of orders were received within 14 days; $66 \%$ of books were received within 31 days. By 2009/10 the average supply time was down to 22 days, with over $25 \%$ of orders received within 14 days and nearly $90 \%$ received within 31 days. This improvement resulted from library purchasing consortia a) including supply times in their specifications; b) being able to get an accurate picture of supply times by averaging them across a large number of libraries, hence discounting local variations; and c) in contract review meetings monitoring performance closely against a service level agreement.

The elimination through the shelf-ready service of backlogs within libraries, coupled with the much shorter supply times achieved, represents a huge improvement in quality of service to the end user in terms of prompt availability of new stock.

This second phase also saw an attempt by the SUPC to introduce a service relatively new to the UK - the so-called slip or approval plan (the term 'slip plan' is preferable: 'on approval' implies that the items can be returned if not approved). Under this arrangement libraries would outsource at least some collection development decisions to the book supplier. Typically the library would define as closely as possible their collection development policies, and record with the supplier parameters such as the subject areas, languages and intellectual level (e.g. undergraduate or research) for purchase. The bookseller would then supply either an electronic record of books proposed to be bought or, in its fullest form, the books themselves without this intermediate stage.

Such slip or approval plans are quite common in the USA, and do decrease the work inherent in book selection by individual libraries, for instance obviating the need to monitor publishers' catalogues or search booksellers' databases and place orders. However there has thus far been little take-up in the UK, probably because of cultural and educational differences, the amount of work necessary to define a library's requirements in sufficient detail, and the generally smaller book budgets enjoyed in the UK (supplier selection in public libraries is dealt with elsewhere in this volume).

The third phase saw a widening of the scope of procurements to other materials. The first of these was e-books, in a groundbreaking agreement negotiated by the SUPC with two major suppliers. The emphasis of this agreement was on the purchase of collections, as well as on procurement of single titles. Such collections provided libraries with a critical mass of over 40,000 e-book titles. These collections, searchable at the level of individual words in the texts, were used by many students as databases, just as electronic journals are. E-books quickly became established as a medium both familiar and useful for students, with modern functionality such as bookmarking and immediate easy availability.

There is an interesting lesson here for collection development. These large collections of ebooks, with good searching functionality, were heavily used by students at all levels: Bournemouth University's experience showed annual totals of over 60,000 user sessions, viewing 826,000 pages from 13,000 individual titles. However the collections did not in large measure contain the recommended reading that librarians would generally have bought. Ease of access and use and availability in quantity, rather than selection by library or academic staff, seem to be the determining factors for our users, a fact that should not be surprising in this era of the Internet.

E-book technology gives a very accurate picture of usage, and has enabled the introduction of so-called 'patron selection' or 'patron driven acquisition' (PDA). Suppliers of e-books are now offering libraries the opportunity to make available a fund to be spent on new e-book titles as they become popular with library users. PDA is becoming increasingly popular: a recent survey of 250 libraries in the USA showed that '32 have PDA programs deployed; 42 
planned to have a program deployed within the next year; and an additional 90 plan to deploy a program within the next three years'

(http://www.libraries.wright.edu/noshelfrequired/?p=932). Librarians are able to impose some restrictions - for instance specifying subjects or ranges of titles; otherwise selection is taken out of the hands of librarians and entrusted to users (see Crowley and Spencer (2011) for other examples of patron selection). As PDA matures, it will be interesting to compare the usage of titles selected by users with the usage of titles selected by librarians or academics.

A further development in this third phase was collaboration on a national level by the regional library purchasing consortia. This scale made it viable to include in the procurement materials generally bought in relatively small quantities even by the largest consortia; examples are out-of-print books and audio-visual materials.

\section{Procurement of Serials}

Thus far we have concentrated on the procurement of books. The procurement of hard-copy serials is in some ways less interesting. As with books, library purchasing consortia have dealt with intermediaries, the serials agents. But this is a business of high volumes and very low margins, now perhaps only $6-7 \%$ (in contrast to the $30-40 \%$ discount on books): there is not the scope for obtaining discounts. Rather the focus is on keeping surcharges down; serials agents have seen their margins eroded as spending on the high-value high-discount scientific, technical and medical (STM) journals has been channelled either through other intermediaries, such as JISC Collections in the UK, or directly to the publishers themselves.

The procurement of e-journals, dealt with elsewhere in this volume, is even more challenging. The pattern varies from country to country. Some, such as the UK (JISC Collections, http://www.jisc-collections.ac.uk/) and Greece (Hellenic Academic Libraries LINK (HEALLink), http://leykada.physics.auth.gr/), take a national approach. Others take a sub-national approach, for instance Consorci de Biblioteques Universitaries de Catalunya (CBUC, http://www.cbuc.es/) in Spain. The USA takes, of course given its size and complexity, a regional approach, but has produced some so-called mega-consortia such as OhioLINK (http://www.ohiolink.edu/). For an interesting analysis of US consortia see Guzzy (2010); for the European experience see Carbone (2010). Organisations such as JISC Collections in the UK and the large regional consortia in the USA have negotiated directly with publishers and obtained large amounts of e-content for prices based on print subscriptions (the socalled Big Deals). These have been welcomed by many: they have delivered large amounts of content for our users. However there are dissenting voices, for instance Ball (2005b), holding that too much power has been ceded to the major publishers. Very large proportions of library budgets, especially in the big research libraries, are committed to a small number of publishers, such as Elsevier and Wiley Blackwell, in Big Deals. These agreements typically included punitive no-cancellation clauses. This, combined with the length and the all-or-nothing nature of such agreements, severely limits libraries' freedom to make or alter purchasing decisions. The result has been severe reductions in spending on monographs and a squeeze on publishers outside the Big Deals.

Further complications arise from the restrictions on use and users enshrined in the licences, discussed above, and the potential cost and difficulty of maintaining access to back-sets after a subscription is cancelled.

\section{The End of Collection Development?}

This chapter in a sense has been retrospective. It has concentrated on the supply of hardcopy books, a market set to decline in importance as book budgets are squeezed and ebooks become available in larger quantities. However the techniques of procurement, particularly specifying needs and monitoring and managing contracts, will remain fundamental. 
Turning to the future, the concept of collection development is under threat.

With the Big Deals power has shifted considerably in the publishers' favour, and freedom to make collection development decisions has been curtailed. If the trend towards national deals and block payments, seen for instance in the Scottish Higher Education Digital Library (SHEDL; for an initial evaluation see Research Information Network (2010)), continues, these decisions will be relinquished even more. As far as procurement is concerned, the Big Deals have simply exposed a malfunction in the market: all publishers are monopolists, sole suppliers of monograph or journal content. Competition, so central to the procurement process, is severely limited, applying essentially only to intermediaries such as booksellers.

A notable response to the power of the publishers' monopoly is the open access movement, which aims to make scholarly literature freely available to all. One route is through open access publishing, where typically the author, or their institution or research funder, pays the cost of peer review and publishing. The content is then freely available without the need for subscription to the journal. The journals themselves may be completely open access or hybrid, publishing a mixture of subscription-based and open-access content. The other route is the deposit of pre- or post-prints of traditionally published materials in the author's institutional repository or in a subject repository such as Arxiv, which covers physics, mathematics and related disciplines (http://arxiv.org/).

The open access movement is still in its infancy, with many obstacles and vested interests to overcome. However, it exemplifies a trend to access to information unmediated by libraries. The Internet is the prime example of this; Google's massive digitisation programme is another; patron selection of e-books yet another. As this trend intensifies, traditional collection development will decline in importance.

In the disintermediated world the librarian's role is changing. It will in my view become increasingly focused not on externally produced resources, but on creating, developing and maintaining repositories of materials, whether learning objects, research data-sets or research outputs such as papers, produced in house in their own institution. Traditionally librarians have sought through the art of collection development to obtain the outputs of the world's scholars and make them available to the scholars of their own institution - an impossible task. However our role is now being reversed: it will be to collect the outputs of our own institution's scholars and make them freely available to the world (for an early elaboration of this idea see Ball and Spice (1996)). This task is capable of achievement and attains the aim of universal availability of scholarship to scholars. However it is not collection development as it has been practised down the years in the print world; that art, it can be argued, will no longer be needed in the era of disintermediation.

\section{Envoi}

This chapter has discussed in some detail the procurement cycle as applied to libraries.

Lessons include:

The importance of support from the procurement profession;

$>$ The continuing need for librarians to develop new skills;

$>$ The need to manage suppliers throughout the life of a contract;

$>$ The remarkable success of library purchasing consortia in driving down prices, decreasing costs through shelf-ready services and improving quality of service in terms for instance of supply times;

$>$ The need to manage the market place, for instance in broadening the scope of procurement to new formats such as e-books.

Issues to consider include:

$>$ The effects on the market place and on library budgets of Big Deals; 
$>$ The advisability of pursuing national deals with monopoly suppliers;

$>$ The demise of collection development in the disintermediated world;

$>$ Transferring decision-making to the end-user;

$>$ The changing role of the librarian, from collector of everything in the world of scholarship to collector and publisher of the product of one's own institution.

\section{References}

Ball, D. (2005a) Managing Suppliers and Partners for the Academic Library, Facet Publishing.

Ball, D. (2005b) Signing Away our Freedom: the implications of electronic resource licences, The Acquisitions Librarian, 18 (35-6), 7-20.

Ball, D. and Spice, C. (1996) The Big Flame: a model for a universal full-text electronic library of research. In Libraries and Associations in the Transient World: New technologies and new forms of co-operation: conference proceedings: Third International Conference "Crimea 96" [The Organizing Committee].

Baudinette, K. (2004) Purchasing Books Collaboratively: the Academic and Research Libraries Acquisitions Consortium: Paper presented at ALIA Acquisitions SA Seminar 'New ways of purchasing, publishing and printing' October 29, 2004, Adelaide, http://hdl.handle.net/2328/3328.

Carbone, P. (2007) Consortium Negotiations with Publishers - Past and Future, Liber Quarterly, 17 (1-40, 98-106.

Crowley, E. and Spencer, C. (2011) Library Resources: Procurement, Innovation and Exploitation in a Digital World. In Dale, P., Beard, J. and Holland, M. (eds), University Libraries and Digital Learning Environments, Ashgate.

Guzzy, J. (2010) U.S. Academic Library Consortia: A Review, Library Papers and Presentations, Paper 8. Available from: http://scholarspace.jccc.edu/lib_pp/8.

Hinton, B. (1993) Librarians as Unacknowledged Legislators, New Library World, 88 (3), 4447.

Nfila, R.B and, Darko-Ampem, K. (2002) Developments in academic library consortia from the 1960s through to 2000: a review of the literature, Library Management, 23 (4/5), 203 212.

Office of Government Commerce (2008) EU Procurement Guidance: Introduction to the EU Procurement Rules, http://www.ogc.gov.uk/key cross-

cutting government policies the policy and legal framework.asp.

Office of Government Commerce, An Introduction to Public Procurement, http://www.ogc.gov.uk/policy_and_standards_framework_introduction_to_public_procureme nt.asp.

Research Information Network (2010), One Year On: Evaluating the Initial Impact of the

Scottish Higher Education Digital Library (SHEDL), http://www.rin.ac.uk/our-work/using-andaccessing-information-resources/evaluating-impact-shedl. 